\title{
High-quality AIN layers grown by hot-wall MOCVD at reduced temperatures
}

\author{
Anelia Kakanakova-Gueorguie, Daniel Nilsson and Erik Janzén
}

\section{Linköping University Post Print}

N.B.: When citing this work, cite the original article.

Original Publication:

Anelia Kakanakova-Gueorguie, Daniel Nilsson and Erik Janzén, High-quality AlN layers grown by hot-wall MOCVD at reduced temperatures, 2012, Journal of Crystal Growth, (338), $1,52-56$.

http://dx.doi.org/10.1016/j.jcrysgro.2011.10.052

Copyright: Elsevier

http://www.elsevier.com/

Postprint available at: Linköping University Electronic Press

http://urn.kb.se/resolve?urn=urn:nbn:se:liu:diva-74117 


\title{
High-quality AIN layers grown by hot-wall MOCVD at reduced temperatures
}

A. Kakanakova-Georgieva*, D. Nilsson, E. Janzén

Department of Physics, Chemistry and Biology (IFM), Linköping University, SE 581 83, Linköping, Sweden

* Corresponding author. Tel.: +4613282649

E-mail address: anelia@ifm.liu.se

\begin{abstract}
We report on a growth of $\mathrm{AlN}$ at reduced temperatures of $1100{ }^{\circ} \mathrm{C}$ and $1200{ }^{\circ} \mathrm{C}$ in a horizontaltube hot-wall metalorganic chemical vapor deposition reactor configured for operation at temperatures of up to $1500-1600{ }^{\circ} \mathrm{C}$ and using a joint delivery of precursors. We present a simple route - as viewed in the context of the elaborate multilayer growth approaches with pulsed ammonia supply - for the AlN growth process on SiC substrates at the reduced temperature of $1200{ }^{\circ} \mathrm{C}$. The established growth conditions in conjunction with the particular in-situ intervening $\mathrm{SiC}$ substrate treatment are considered pertinent to the accomplishment of crystalline, relatively thin, $700 \mathrm{~nm}$, single AlN layers of high-quality. The feedback is obtained from surface morphology, cathodoluminescence and secondary ion mass spectrometry characterization.
\end{abstract}

\section{Keywords:}

A3: Metalorganic chemical vapor deposition

B1: Nitrides

B2: Semiconducting III-V materials 


\section{Introduction}

The metalorganic chemical vapor deposition (MOCVD) growth of AlGaInN layers is essential for the development of device structures such as light-emitting diodes (LEDs) in the violet-bluegreen wavelength region of the spectrum. The attained good understanding - including computational modeling - of the gas-phase transport phenomena, dominant gas-phase and surface reaction mechanisms, has supported the optimization of AlGaInN MOCVD processes in various types of reactors [1]. The quality of the AlGaInN epitaxial layers grown on foreign substrates is yet inadequate to fully explore the physical properties of the respective semiconductor materials. This is particularly relevant for the AlN epitaxial layers, which generally comprise high density of dislocations, and high concentration of point defects. It is difficult to grow high-quality AlN epitaxial layers as high temperatures, $>1200^{\circ} \mathrm{C}$, and low V/III ratios are required $[2,3]$. While extremely low ammonia, $\mathrm{NH}_{3}$, flow rates of $\sim 10-100 \mathrm{ml} / \mathrm{min}$, and low V/III ratios of $\sim 10-116$ have been applied $[4,5]$, the $\mathrm{NH}_{3}$ excess during growth should be high enough to achieve a good quality of the crystalline AlN [6]. The design and optimization of AlN MOCVD process, that manages the involved heat, gas-phase transport and gas-phase and surface reaction complexity, is a recognized issue in the research of AlN growth. It is reflected in the fact, that the surface morphology and cathodoluminescence (CL) of AlN layers grown by MOCVD at low pressures, < $200 \mathrm{mbar}$, low $\mathrm{V} / \mathrm{III}$ ratios, $<2000$, and reduced temperatures, $<1300^{\circ} \mathrm{C}$, were demonstrated to depend on the reactor configuration, including horizontal- or vertical- type flow with the horizontal-type flow being prone to gas-phase reactions between precursors [7].

In this paper, we discuss surface morphology and CL of AlN epitaxial layers grown in a horizontal-tube hot-wall MOCVD reactor configured for operation at temperatures of up to 1500$1600{ }^{\circ} \mathrm{C}[8]$. Here we report on a growth of AlN at reduced temperatures of $1100^{\circ} \mathrm{C}$ and $1200^{\circ} \mathrm{C}$, which are the maximal attainable by most of the present MOCVD systems. 
The growth of AlN at reduced temperatures is often enabled in conjunction with the alternating supply of precursors (trimethylaluminum, TMAl, and $\mathrm{NH}_{3}$, respectively) assuming enhanced surface migration and consequent lateral growth, which are for the benefit of the material quality [9]. Different modifications of the so referred migration enhanced epitaxy have been suggested, especially in the context of the fabrication of elaborate, thick, $\sim 4 \mu \mathrm{m}, \mathrm{AlN}$ templates on sapphire substrates for the better performance of deep-UV LEDs [10]. The growth of AlN at reduced temperatures has also been enabled by alternating between two-dimensional and three-dimensional growth modes, for which the conditions have been adjusted by changing both, the temperature and V/III ratio, together with a pulsed supply of $\mathrm{NH}_{3}$, and achieving thick, $1.5 \mu \mathrm{m}$, crack-free, multilayer AlN structure on SiC substrate [11].

Our approach to the growth of AlN epitaxial layers involves joint delivery of both precursors. We show that the established growth conditions in conjunction with the particular insitu intervening $\mathrm{SiC}$ substrate treatment are pertinent to the accomplishment of crystalline AlN of device quality within relatively thin, $<700 \mathrm{~nm}$, single layers, at the reduced temperature of $1200^{\circ} \mathrm{C}$.

\section{Experimental}

The AlN growth was performed in a horizontal-tube hot-wall MOCVD reactor [GaN VP508GFR, Aixtron $\mathrm{AB}$ ] at a process pressure of 50 mbar and process temperatures of 1100 and $1200^{\circ} \mathrm{C}$. The process temperature is measured by a two-color pyrometer focused into a hole drilled in the roof of the TaC-coated graphite susceptor (black-body radiation approximation). The substrate is heated by physical contact with the RF-heated susceptor and the additional radiative heating from the susceptor surfaces. The flow rates of carrier gases, $\mathrm{H}_{2}$ and $\mathrm{N}_{2}$, were optimized for high efficiency and uniformity of the AlN growth on 2" SiC wafers [8]. The SiC substrates used in this study were of the $4 \mathrm{H}$ polytype and nominally on-axis. The substrates were treated in-situ the 
reactor in only $\mathrm{H}_{2}$ flow at the low process pressure of 50 mbar, and a temperature of $1250^{\circ} \mathrm{C}$, which also served to condition the susceptor prior to the $\mathrm{AlN}$ growth. $\mathrm{NH}_{3}$ and TMAl were used as precursors at a flow-rate-ratio $\mathrm{NH}_{3} / \mathrm{TMAl}$ of $\sim 2000 . \mathrm{NH}_{3}$ was introduced into the deposition zone when the temperature was ramped down to its set value for the AlN growth. The introduction of TMAl was delayed by further 10 minutes. Secondary ion mass spectrometry (SIMS) with Cs+ primary ion bombardment and negative secondary ion detection was employed to obtain concentration depth profiles of oxygen and other major impurities in the AlN layers. The instrument conditions were optimized for overall depth resolution and sensitivity. The quantification of the impurity concentrations was performed using proprietary data processing method PCOR-SIMS $^{\mathrm{TM}}$ [12]. Secondary electron microscopy (SEM) images, CL panchromatic images and spectra from the AlN layers were obtained in a field-emission gun scanning electron microscope with CL attachment (Leo1550 MonoCL2 system, Oxford Res. Instr.) and equipped with a continuous flow liquid helium cold stage. The CL images and spectra were recorded at $5 \mathrm{~K}$ and $10 \mathrm{kV}$. The system features precision light collection optics which is directly coupled to the SEM-chamber-mounted photomultiplier tube (for panchromatic, all wavelengths, imaging), alternatively monochromator. Spectra collection was performed with 1800 lines/mm $250 \mathrm{~nm}$ blaze grating. Spectral correction for instrumental response was not available. The surface topography of the layers was obtained by atomic force microscopy (AFM) in a tapping mode (Veeco Dimension 3100 Scanning Probe Microscope) and it is presented next for AlN layers of similar thickness of $~ 700 \mathrm{~nm}$. (Fig. 1).

\section{Results and Discussions}

The surface topography of the layers is eminently receptive to the process temperature, in this case $1100^{\circ} \mathrm{C}$ and $1200^{\circ} \mathrm{C}$, reinforcing it as one of the most important parameters in the MOCVD growth of AlN. The surface topography of the AlN layer grown at $1100{ }^{\circ} \mathrm{C}$ is represented by 
hexagonal-shaped, spiral-like, and flat-top features covering dominant surface area (Fig. 1(a)). Important surface reactions, related to the decomposition of growth limiting species [13] and diffusion, intensified at $1200^{\circ} \mathrm{C}$, contribute to the thorough merging of these growth features accommodating a flat surface with a root-mean-square $(\mathrm{rms})$ roughness of $0.12 \mathrm{~nm}$ over an area of $5 \times 5 \mu \mathrm{m}^{2}$ (Fig. 1(b)). Already an rms-value of $0.3 \mathrm{~nm}$ is considered small enough for device applications [14].

The observation of the hexagonal-shaped, spiral-like features relates to a dislocationmediated growth mechanism at the initial stage and certainly reflects the conditions for the in-situ treatment of the $\mathrm{SiC}$ substrate following the description in the experimental part. Priority in this treatment was given for eliminating any residual oxides on the $\mathrm{SiC}$ substrate surface prior to the AlN growth. The low process pressure of 50 mbar is prompted to promote a low supersaturation of the $\mathrm{SiC}$ vapor over the heated substrate surface initiating preferential etching at crystal lattice defects and aided by hydrogen, known to generate the appearance of hexagonal-shaped etch pits at screw dislocations on the SiC surface [15]. The appearance of the SiC surface is further furnished by its exposition to $\mathrm{NH}_{3}$ introduced at the end of the temperature ramp-down step and ahead of the TMAl introduction. SiC surface exposition to $\mathrm{NH}_{3}$ is known to cause a smoothening effect attributed to a combination of nitrogen chemisorption and etching [16]. Etch pits and depressions, with the associated steps, can instantly be identified for an in-situ pre-growth treatment at a slightly exaggerating temperature of $1280^{\circ} \mathrm{C}$, for which the lateral size of the hexagonal-shaped etch pits has significantly been enlarged (the insert in Fig. 1(c)). Consequent AlN growth in the presence of the surface intersection of screw-component treading dislocations causes spiral growth. Presumably, the intervening $\mathrm{SiC}$ substrate treatment creates conditions for the propagation of steps arising from an array of crystalografically aligned spirals, which thus can merge with less strain and defects along the vertical boundaries. The crystalline quality of the $700 \mathrm{~nm}$-thick AlN layer grown at $1200^{\circ} \mathrm{C}$ is manifested in high-resolution X-ray diffraction by narrow $\omega$-rocking curves, sensitive to the tilting of the lattice planes. The symmetric (002) and 
asymmetric (103) Bragg reflections each, yields a full-width-at-half-maximum (FWHM) of 195 $\operatorname{arcsec}$.

The SEM images of the AlN layers grown at $1100^{\circ} \mathrm{C}$ and $1200^{\circ} \mathrm{C}(\mathrm{Fig} .3)$ are suggestive for a rather smooth surface morphology inattentive to their distinct surface topography over a zscale of 3 - $5 \mathrm{~nm}$ as measured by AFM (Fig. 1). The SEM signal is formed deeper into the layers generating subsurface structure information that adds to the exclusively surface sensitive AFM observation [17]. While both layers are essentially continuous, only the very top surface topography varies.

The SEM surface morphology of the studied AlN layers does display certain differences. The growth at $1200^{\circ} \mathrm{C}$ creates nearly featureless surface (Fig. 2(a)), unlike the growth at $1100^{\circ} \mathrm{C}$ for which the surface is populated with pits of dark contrast (Fig. 2(b)). Given the characteristic shape, regular or distorted hexagons, and lateral size, $~ 50$ to $200 \mathrm{~nm}$, as can be obtained from the SEM image, the observed surface pits can presumably be associated with defects such as nanopipes. The AFM section analysis for occasional pits, including the one indicated in Fig. 1(a), is consistent with the interpretation for the pipe-shaped contour of the defects associated with the observed surface pits. The pits of dark contrast in the SEM images correspond to pits of extremely bright contrast in the respective panchromatic CL images (Figs. 2(c) and 2(d)). Previously, strong CL emission has been recognized from the interior of defects like micropipes in $\mathrm{SiC}$ substrates. Due to the geometry of the defect, there is a relatively large surface area for emission of photons being available within the pipe [18]. We note that without any discerning cross-sectional observations, nanopipes with (1010) walls, extending along the growth direction with a constant diameter, cannot be clearly distinguished from a related type of defects, the near surface pinholes with facets along the slow-growth (1011) planes, which can occur at any stage of growth when surface roughness develops at places where growth islands meet each other, a dislocation intersects the growth surface, or at impurity clusters [19]. A rational explanation for the high-density of the hexagonal-shaped surface pits and the presumably associated with them 
nanopipes/large pinholes, during the growth at $1100^{\circ} \mathrm{C}$ involves consideration about kinetic effects including surface migration of impurity atoms during growth. For example, in the case of $\mathrm{GaN}$, it was found that oxygen has a tendency to segregate to the (1010) surface preventing these internal surfaces to grow further thus forming nanopipes with density that relates to the initial oxygen concentration in the bulk of the material [20].

While there is oxygen and carbon with rather extended concentration gradient within the AlN layer grown at $1100^{\circ} \mathrm{C}, \mathrm{AlN}$ layers grown at $1200^{\circ} \mathrm{C}$ (and $1300^{\circ} \mathrm{C}$ ) do not contain oxygen and other major impurities beyond instrumental detection limits (Fig. 3). This follows a previously reported trend of diminishing the amount of the incorporated oxygen and other major impurities in AlN with increasing growth temperature in the range of $1100-1600^{\circ} \mathrm{C}$ [21].

The established growth conditions in accord with the temperature and flow-rate of precursors, obviously determine growth kinetics that essentially prevents any major impurity contamination of the $\mathrm{AlN}$ already for the reduced temperature of $1200^{\circ} \mathrm{C}$ with certain implication for any successful doping of AlN and high-Al-content AlGaN [22]. It is conceived from firstprinciples calculations [23] that oxygen impurity incorporation during growth enhances the formation of cation vacancies to form energetically stable $\mathrm{V}_{\mathrm{Al}}$ or $\mathrm{V}_{\mathrm{Al}} \mathrm{O}_{\mathrm{N}}$ complexes, which can reduce the conductivity, particularly in high-Al-content AlGaN and AlN [24], as these acceptorlike defects act as compensating centers. Efficient self-compensation of carbon acceptors by carbon donors in AlN resulting in quenching of doping efficiency is predicted by quantum molecular dynamics calculations [25]. Conductivity control in high-Al-content AlGaN and AlN benefits by creating growth conditions, which drive the reduction of the amount of the incorporated oxygen and carbon impurity. We can confirm the achievement of low-resistivity Mg-doped $\mathrm{Al}_{0.85} \mathrm{Ga}_{0.15} \mathrm{~N}$ layers grown by hot-wall MOCVD under similarly optimized growth conditions [26].

Apart from the nanometer-size pits of extremely bright contrast, the panchromatic CL images of the studied AlN layers generally show contrast distribution across larger areas. The CL 
intensity is more homogeneously distributed across the panchromatic CL image of the AlN layer grown at $1200^{\circ} \mathrm{C}$ (Fig. 2(d)), indicative of more uniform material properties.

Typical CL spectra collected from volumes within bright and darker areas are plotted in Fig. 4. The spectra display the AlN exciton-recombination-related near-band-edge emission (NBE) at $\sim 208 \mathrm{~nm}$ in the deep-ultraviolet region with competitive defect-related emission in the ultraviolet (UV) region. The two spectra in Fig. 4 are rather identical with the NBE emission being of weaker intensity in the spectrum collected from the volume within darker area. Generally, darker areas in the CL images are identified as regions where minority carriers are depleted due to high non-radiative recombination velocity at crystal defects [27]. Since the CL is not corrected for any UV response of the system, defining the relative contribution of any of the NBE- or defect-related- emission to the yielded CL intensity or comparing peak intensities at different wavelengths in a same spectrum is not relevant. Yet, the NBE emission in the deep-UV, which is the most attenuated light as it passes through the CL system optics, is dominating the spectra, which underlines the high crystalline quality of the AlN layer grown at $1200^{\circ} \mathrm{C}$.

\section{Conclusions}

For the growth of AlN, the horizontal-tube hot-wall MOCVD can operate in the temperature range of $1100-1200^{\circ} \mathrm{C}$ and up to $1500-1600^{\circ} \mathrm{C}$, being an advantage for exploring the growth and material properties of $\mathrm{AlN}$ at different temperature limits in a same reactor. In the present paper, we presented a simple route - as viewed in the context of the elaborate multilayer growth approaches with pulsed ammonia supply - for the AlN growth process on SiC substrates at the reduced temperature of $1200^{\circ} \mathrm{C}$ together with the joint delivery of both, TMAl and $\mathrm{NH}_{3}$, precursors. The established growth conditions, including the temperature of $1200^{\circ} \mathrm{C}$ in this case, flow-rate of precursors and in conjunction with the particular in-situ intervening SiC substrate treatment are considered pertinent to the accomplishment of crystalline, relatively thin, $\sim 700 \mathrm{~nm}$, 
single AlN layers of high-quality. It is reflected in the rms-value of $0.12 \mathrm{~nm}$ over $5 \times 5 \mu \mathrm{m}^{2}$ area, major impurities below SIMS detection limits, and intense and rather uniformly distributed exciton-recombination-related near-band-edge cathodoluminescence.

\section{Acknowledgements}

The Swedish Research Council (VR) and The Swedish Foundation for Strategic Research (SSF) are gratefully acknowledged. The authors thank M. Xie and Dr. V. Darakchieva for the highresolution XRD measurements performed at Linköping University. 


\section{References}

1) M. Dauelsberg, E.J. Thrush, B. Schineller, J. Kaeppeler, in: M. Razeghi, M. Henini (Eds.) Optoelectronic Devices: III-Nitrides, Elsevier Ltd., ISBN: 0-08-044426-1, 2004, Chap. 4.

2) H.X. Jiang, J.Y. Lin, in: M. Razeghi, M. Henini (Eds.) Optoelectronic Devices: III-Nitrides, Elsevier Ltd., ISBN: 0-08-044426-1, 2004, Chap. 7.

3) K. Cheng, S. Degroote, M. Leys, F. Medjdoub, J. Derluyn, B. Sijmus, M. Germain, G. Borghs, J. Cryst. Growth 315 (2011) 204.

4) A. Kakanakova-Georgieva, A. Kasic, C. Hallin, B. Monemar, E. Janzén, Phys. Status Solidi C $2(2005) 960$.

5) M. Imura, K. Nakano, N. Fujimoto, N. Okada, K. Balakrishnan, M. Iwaya, S. Kamiyama, H. Amano, I. Akasaki, T. Noro, T. Takagi, A. Bandoh, Jpn. J. Appl. Phys. 46 (2007) 1458.

6) A.V. Lobanova, K.M. Mazaeva, R.A Talalaev, M. Leys, S. Boeykens, K. Cheng, S. Degroote, J. Cryst. Growth 287 (2006) 601.

7) A. Dadgar, A. Krost, J. Christen, B. Bastek, F. Bertram, A. Krtschil, T. Hempel, J. Bläsing, U. Haboeck, A. Hoffmann, J. Cryst. Growth 297 (2006) 306.

8) A. Kakanakova-Georgieva, R. R. Ciechonski, U. Forsberg, A. Lundskog, E. Janzén, Cryst. Growth \& Design 9 (2009) 880.

9) R.G. Banal, M. Funato, Y. Kawakami, Appl. Phys. Lett. 92 (2008) 241905.

10) H. Hirayama, S. Fujikawa, N. Noguchi, J. Norimatsu, T. Takano, K. Tsubaki, N. Kamata, Phys. Status Solidi A 206 (2009) 1176.

11) Z. Chen, S. Newman, D. Brown, R. Chung, S. Keller, U.K. Mishra, S.P. Denbaars, S. Nakamura, Appl. Phys. Lett. 93 (2008) 191906.

12) Evans Analytical Group ${ }^{\circledR}($ EAG), http://www.eaglabs.com

13) T.G. Mihopoulos, V. Gupta, K. F. Jensen, J. Cryst. Growth 195 (1998) 733.

14) N. Onojima, J. Suda, H. Matsunami, Appl. Phys. Lett. 80 (2002) 76. 
15) C. Hallin, F. Owman, P. Mårtensson, A. Ellison, A. Konstantinov, O. Kordina, E. Janzén, J. Cryst. Growth 181 (1997) 241.

16) J.T. Torvik, M.W. Leksono, J.I. Pankove, C. Heinlein, J.K. Grepstad, C. Magee, J. Electron. Materials 28 (1999) 234.

17) Y. Golan, X.H. Wu, J.S. Speck, R.P. Vaudo, V.M. Phanse, Appl. Phys. Lett. 73 (1998) 3090.

18) M.F. MacMillan, L. Hultman, C. Hallin, I.G. Ivanov, A. Henry, E. Janzén, S.A. Galloway, Mater. Sci. Forum 264-268 (1998) 653.

19) Z. Liliental-Weber, Y. Chen, S. Ruvimov, J. Washburn, Phys. Rev. Lett. 79 (1997) 2835.

20) J. Elsner, R. Jones, M. Haugk, R. Gutierrez, Th. Frauenheim, M.I. Heggie, S. Öberg, P.R. Briddon, Appl. Phys. Lett. 73 (1998) 3530.

21) M. Imura, H. Sugimura, N. Okada, M. Iwaya, S. Kamiyama, H. Amano, I. Akasaki, A. Bandoh, J. Cryst. Growth 310 (2008) 2308.

22) R. Dalmau, B. Moody, R. Schlesser, S. Mita, J. Xie, M. Feneberg, B. Neuschl, K. Thonke, R. Collazo, A. Rice, J. Tweedie, Z. Sitar, J. Electrochem. Soc. 158 (2011) H530.

23) C.G. Van de Walle, J. Neugebauer, J. Appl. Phys. 95 (2004) 3851.

24) M.L. Nakarmi, K.H. Kim, K. Zhu, J.Y. Lin, H.X. Jiang, Appl. Phys. Lett. 85 (2004) 3769.

25) P. Bogusławski, E.L. Briggs, J. Bernholc, Appl. Phys. Lett. 69 (1996) 233.

26) A. Kakanakova-Georgieva, D. Nilsson, M. Stattin, U. Forsberg, Å. Haglund, A. Larsson, E. Janzén, Phys. Status Solidi RRL 4 (2010) 311.

27) S.J. Rosner, E.C. Carr, M.J. Ludowise, G. Girolami, H.I. Erikson, Appl. Phys. Lett. 70 (1997) 420. 


\section{Figure captions:}

Fig. 1 AFM topographies from samples representing: (a) AlN layer grown at $1100^{\circ} \mathrm{C}$; scan size of image: $5 \times 5 \mathrm{~m}^{2}$; z-scale: $5 \mathrm{~nm}$; The section analysis for the particular pit on the image indicates a diameter of $\sim 180 \mathrm{~nm}$ and a depth of $\sim 100 \mathrm{~nm}$ below the layer surface; The actual depth may be underestimated due to the limited vibration amplitude of the oscillating cantilever; (b) AlN layer grown at $1200^{\circ} \mathrm{C}$; scan size of image: $5 \times 5 \mathrm{~m}^{2}$; rms value over the $5 \times 5 \mu \mathrm{m}^{2}$ scan: $0.12 \mathrm{~nm}$; $\mathrm{z}$ scale: $3 \mathrm{~nm}$; (c) $4 \mathrm{H}-\mathrm{SiC}$ substrate surface treated at $1280^{\circ} \mathrm{C}$ in a hydrogen flow; scan size of image: $30 \mathrm{x} 30 \mu \mathrm{m}^{2}$; z-scale: $7 \mathrm{~nm}$; The insert is a $3 \times 3 \mu \mathrm{m}^{2}$ image of a hexagonal-shaped etch pit with a side measure of $\sim 780 \mathrm{~nm}$.

Fig. 2 SEM images from the surface of AlN layers grown at (a) $1200^{\circ} \mathrm{C}$ and (b) $1100^{\circ} \mathrm{C}$. Respective panchromatic CL images are shown in (c) and (d).

Fig. 3 Typical SIMS depth profiles of impurity concentrations in AlN layers grown at (a) $1200^{\circ} \mathrm{C}$ (and $1300^{\circ} \mathrm{C}$ ) and (b) $1100^{\circ} \mathrm{C}$; as the zero of the depth scale matches the sample surface, concentration gradients within $\sim 20 \mathrm{~nm}$ below the sample surface are considered irrelevant; quantification is valid only in the AlN layer and not within the SiC substrate.

Fig. 4 CL spectra obtained from bright (red curve) and dark (blue curve) area within AIN layer grown at $1200^{\circ} \mathrm{C}$. 
Fig. 1
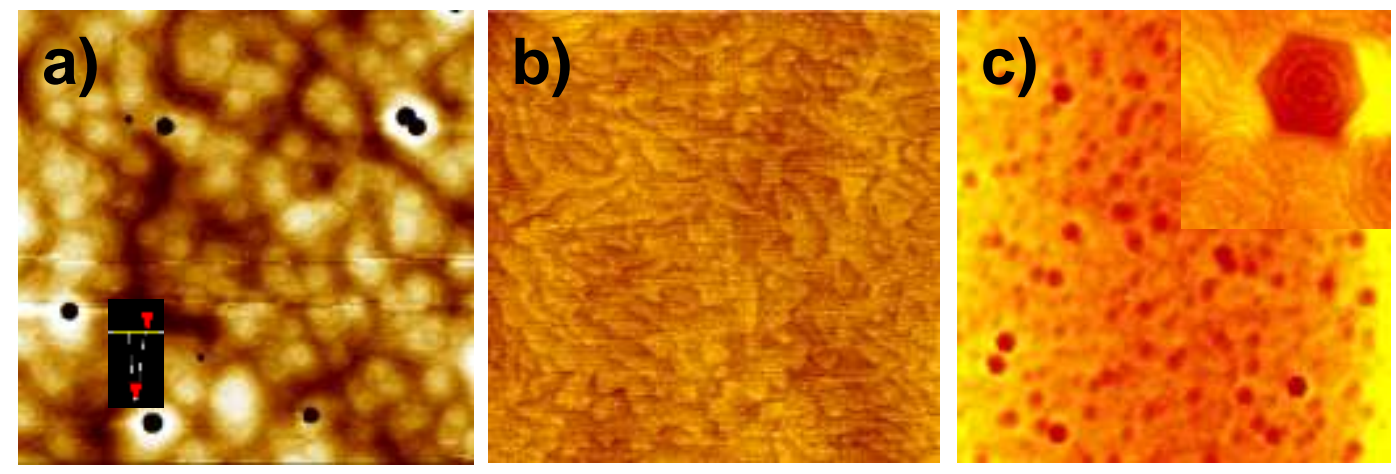
Fig. 2
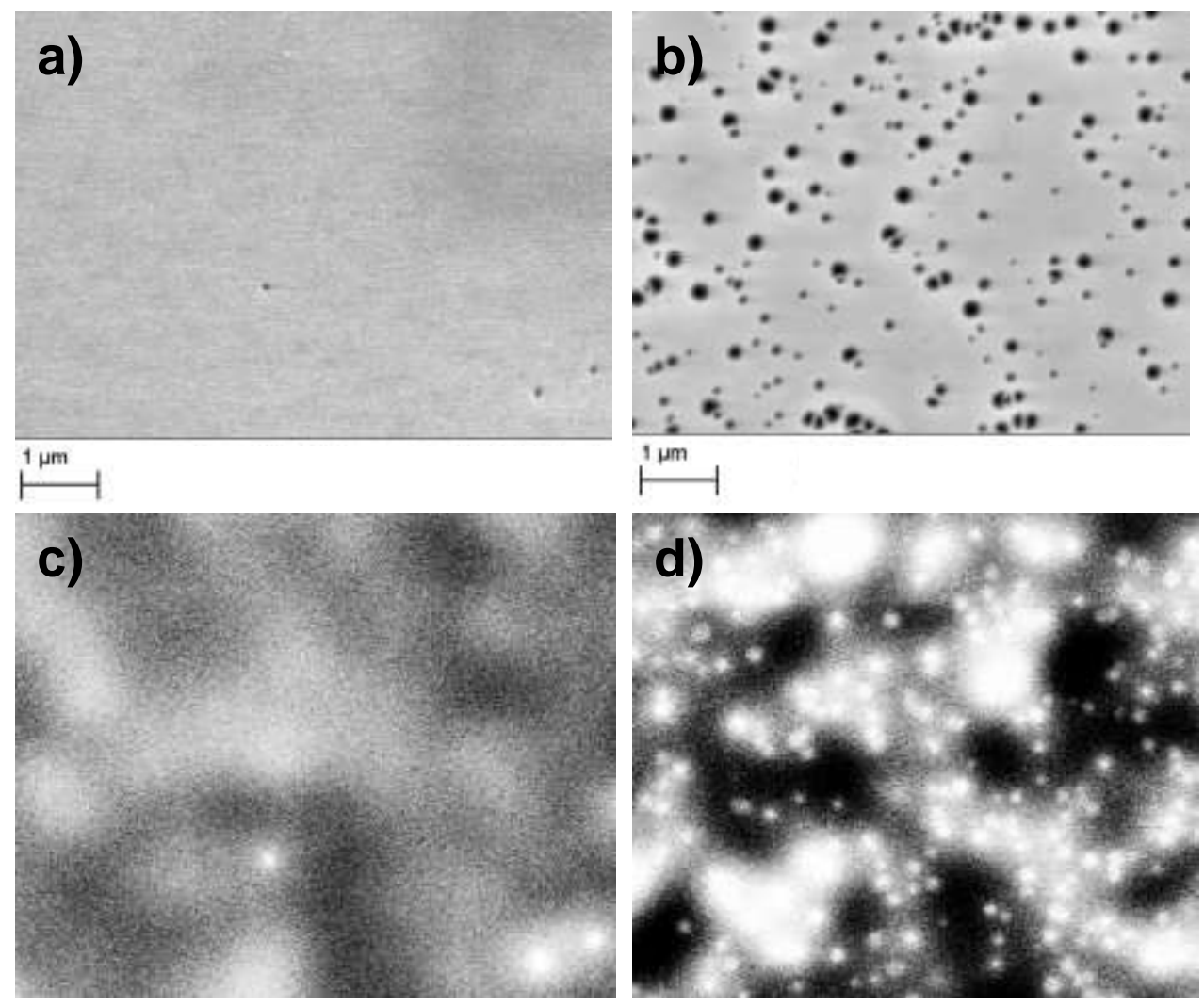
Fig. 3
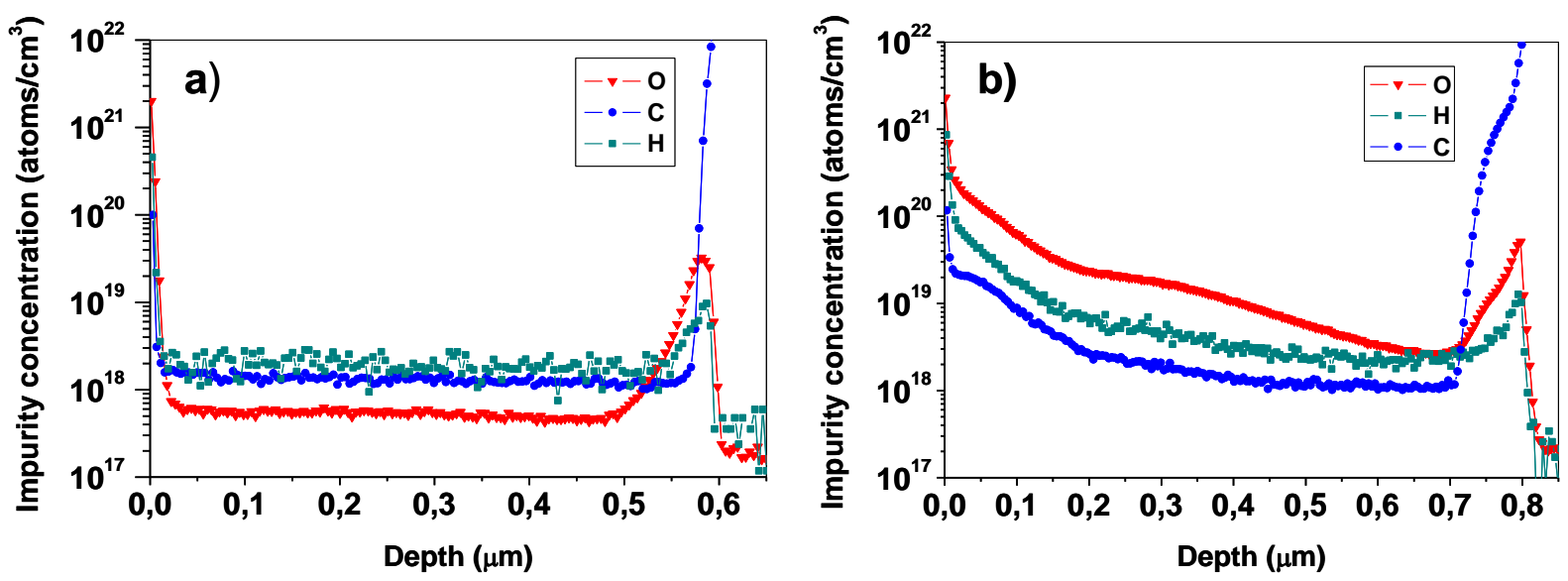
Fig. 4

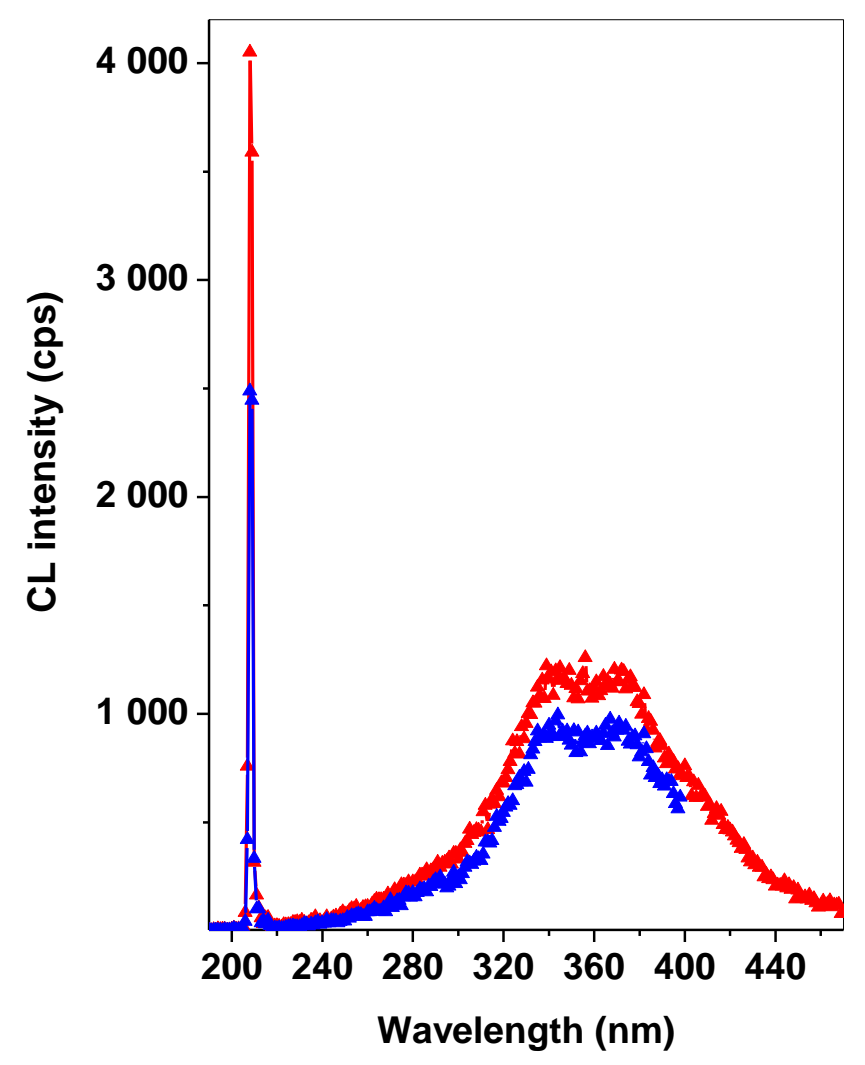

